\title{
Influence of Long-Term Changes in the Large-Scale Sea Level Pressure Field on the Wind Regime and the Wind Stress Curl in the Black Sea
}

\author{
I. G. Shokurova ${ }^{凶}$, A. A. Kubryakov, M. V. Shokurov \\ Marine Hydrophysical Institute of RAS, Sevastopol, Russian Federation \\ 凶igshokurova@mail.ru
}

\begin{abstract}
Purpose. The paper is aimed at studying the relationship between the wind regime and the wind stress curl in the Black Sea and the long-term changes in the large-scale sea level pressure field in winter months.

Methods and Results. The data on wind speed and sea level pressure in January - February from the NCEP/NCAR reanalysis for 1948-2018 are used. Based on the 6-hour data, the synoptic conditions accompanied by high and low values of the wind stress curl in the sea were determined. The synoptic situations in which a vast anticyclone is located north and northeast of the sea, and the area of low pressure - to the southwest of the sea in the Mediterranean region, are accompanied by the northeast and east winds, and by the cyclonic curl predominance. On the contrary, passing of the cyclones to the north of the sea and increase of pressure to the south and southwest are followed by the westerly and southwesterly winds, and by the anticyclonic curl predominance. Extremely high monthly mean values of the cyclonic curl were observed in those years, when the area occupied by the Siberian anticyclone increased and expanded westward, so that the Black Sea was on the southwestern periphery of its spur. Extremely low values of the anticyclonic curl were noted when the Azores anticyclone area expanded to the Mediterranean region. The wind stress curl changes on the multidecadal scales have shown its relation to the global changes in the field of the sea level pressure and the sign of the pressure anomalies at the low latitudes.

Conclusions. The opposite sign of the surface pressure anomalies to the northeast and southwest of the sea is accompanied by the highest values of the wind stress curl.
\end{abstract}

Keywords: Black Sea, sea level pressure, wind direction, wind stress curl, long-term variability

Acknowledgements: the investigation was carried out within the framework of the state tasks No. 0827-2019-0001 "Fundamental studies of processes of interaction in the ocean - atmosphere system which determine the regional spatial-temporal variability of the natural environment and climate" and No. 0555-2021-0006 "Development of innovative methods and software, data processing and technical means of research of hydrophysical, biogeochemical, optical characteristics of the marine environment, including remote sensing methods".

For citation: Shokurova, I.G., Kubryakov, A.A. and Shokurov, M.V., 2021. Influence of Long-Term Changes in the Large-Scale Sea Level Pressure Field on the Wind Regime and the Wind Stress Curl in the Black Sea. Physical Oceanography, [e-journal] 28(2), pp. 165-179. doi:10.22449/1573-160X2021-2-165-179

DOI: $10.22449 / 1573-160 X-2021-2-165-179$

(C) I. G. Shokurova, A. A. Kubryakov, M. V. Shokurov, 2021

(C) Physical Oceanography, 2021

\section{Introduction}

In order to analyze the seasonal and long-term variability of current velocity and vertical mixing in the Black Sea, the information on the external wind forcing variability is required [1]. The seasonal variation of the Black Sea circulation intensity largely depends on the wind curl value above its water area [2, 3]. An increase in cyclonic wind curl in winter leads to an intensification of the Rim Current, which has a cyclonic sign, and its weakening in summer is accompanied 
by a weakening of the current velocity, its disintegration into two gyres or a number of of eddies [4, 5]. A positive relationship between the intensity of surface currents and wind curl was also revealed for interannual variability based on the analysis of time series of current kinetic energy [6].

The value and sign of wind curl distribution above the sea are determined by the background large-scale synoptic situation, as well as regional orographic and thermal effects [3, 6-8]. The Black Sea can be located in the center or at the periphery of large-scale cyclones and anticyclones moving from the west [9-11]. In addition, synoptic cyclones formed at the Mediterranean Sea can pass and intensify above the sea [9]. Due to regional orographic effects, and in particular the wind flow around the Caucasus Mountains, the mesoscale cyclonic formations, mainly forming in the eastern part of the sea, appear [12, 13]. Seasonal variations in the contrasts of buoyancy fluxes in the atmosphere above the sea and the surrounding land also contribute to wind curl. In winter, due to the warmer sea, this contrast leads to an increase in cyclonic curl [2, 3, 14, 15].

Statistical analysis of the wind data revealed the presence of a relationship between the value and spatial distribution of wind stress curl with the direction of the wind prevailing above the sea [16-18]. This dependence is largely related to the small size of the sea, the presence of high extended mountains on the Black Sea eastern and southern coasts and mountains on the Crimean Peninsula (Fig. 1, a) $[3,8,19]$. The velocity shear arising from the wind flow around the mountains leads to the occurrence of the wind field inhomogeneity and the appearance of curl. The flow around the Caucasus Mountains by the most frequent northeastern winds in the region leads to the fact that in the eastern part of the sea, almost throughout the year, the cyclonic curl of the wind prevails with the highest values in the winter season. This effect is noted in [7, 13, 17] based on the data of regional models, reanalyses [20, 21] and satellite scatterometers [22, 23], regardless of the data resolution (Fig. 1, $b-e$ ). The predominance of cyclonic curl in the eastern part of the sea is also revealed when analyzing its long-term variability [24]. The magnitude of curl is also affected by the wind velocity value due to an increase in the velocity shear during strong winds [13].

In its turn, the direction of the prevailing wind flow above the sea is determined by the position of large-scale cyclones and anticyclones [9, 10]. In [9] on the base of synoptic maps for 10-year period 1946-1955, it was demonstrated that each wind direction corresponds to a certain large-scale distribution of surface atmospheric pressure.

In this study, the problem for determining the regional features of the relationship between the distribution of surface pressure and the curl of the wind stress in the Black Sea according to data for January - February is posed. For this purpose, a chain of relationships is analyzed: large-scale synoptic situation - wind direction - wind stress curl. The analysis of situations in which extreme values of curl occur is carried out. The inter-decadal variability of the surface pressure anomaly fields is analyzed. 

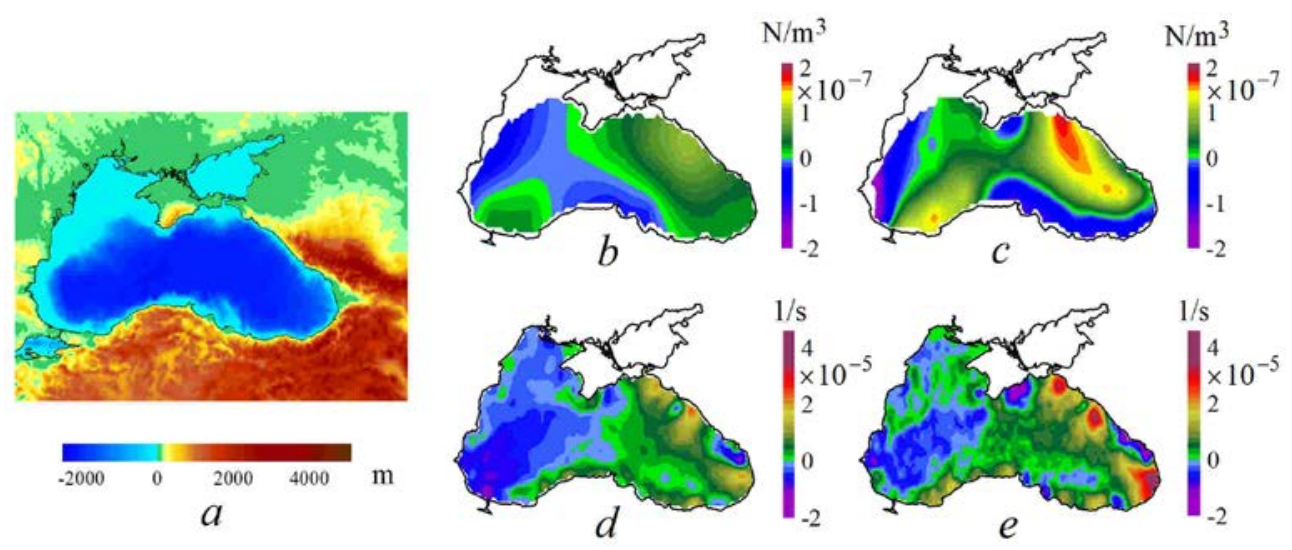

F i g. 1. Orography of the Black Sea region based on the ETOPO2v2 data [https://www.ngdc.noaa.gov/mgg/global/etopo2.html] (a); multiyear mean distribution of: the wind stress curl [17] based on the NCEP/NCAR data for 1948-2018 $\left(1.905 \times 1.875^{\circ}\right)$ [20] $(b)$ and the ERA Interim data for $1979-2016\left(0.75 \times 0.75^{\circ}\right)$ [21] $(c)$, the wind curl [13] based on the QuikSCAT data for 2000-2009 (12.5 × 12.5 km) [22] (d) and the ASCAT data for 2010-2016 (12.5 × 12.5 km) [23] $(e)$

The selection of data for the reanalysis study was determined by the requirement for the series duration. As a rule, long series of reanalysis data have low spatial resolution. A preliminary comparison [18] of the interannual variability of the basin-averaged wind stress curl obtained from the reanalyses data (with different spatial resolution and different row length) NCEP/NCAR (1.905 $\times 1.875^{\circ}$, since 1948) [20] and ERA Interim $\left(0.75 \times 0.75^{\circ}\right.$, since 1979) [21] demonstrated a high consistency of the results, which provided the use of NCEP/NCAR reanalysis data.

\section{Research data and methods}

In this work the following NCEP/NCAR reanalysis data for 1948-2018 [20] were used:

- 6-hour wind velocity data at $10 \mathrm{~m}$ above the sea level with $1.905 \times 1.875^{\circ}$ spatial resolution and 6-hour surface pressure data with $2.5 \times 2.5^{\circ}$ spatial resolution for an area limited by $30-60^{\circ} \mathrm{N}$ and $10-60^{\circ}$ E, including the Black Sea region;

- monthly average data on surface pressure with $2.5 \times 2.5^{\circ}$ spatial resolution over the entire territory of the Earth.

For each 6-hour period, the wind stress $\boldsymbol{\tau}=\left(\tau_{x}, \tau_{y}\right)$ and its curl $\operatorname{rot}_{z} \boldsymbol{\tau}$ were calculated and the direction of the prevailing wind over the sea was determined.

Wind stress was calculated using the aerodynamic formula $\tau=\rho_{a} C_{d}|\mathbf{V}| \mathbf{V}$, where $\rho_{a}$ is the air density; $C_{d}$ is a dimensionless coefficient of the sea surface resistance; $\mathbf{V}=(u, v)$ is wind velocity $(\mathrm{m} / \mathrm{s})$. The coefficient $C_{d}$ was calculated using the formula from [25]. 
The wind stress curl $\operatorname{rot}_{z} \tau=\partial \tau_{y} / \partial x-\partial \tau_{x} / \partial y$ was calculated at the grid nodes, which are the centers of the squares in which the initial wind data are located. The basin-averaged were calculated in the area bounded by $50 \mathrm{~m}$ isobath.

The direction of the prevailing wind over the sea was determined by averaging $u$ and $v$ components of wind vector $\mathbf{V}=(u, v)$ according to the data falling on the sea area. The direction of the obtained vector was tied to one of 8 main directions: north (C), north-east (NE), east (V), southeast (SE), south (S), southwest (SW), west (W) and northwest (NW). Thus, a specific wind direction was assigned to each 6-hour wind stress curl field and sea level pressure field.

The average sea level pressure fields corresponding to the winds of main geographic directions were calculated based on the grouping of 6-hour fields with a certain wind direction and their subsequent averaging. Also, by averaging, the values of the sea-averaged wind stress curl corresponding to each direction were calculated. The occurrence frequency of situations with the wind of certain direction was calculated as a percentage of the total number of situations.

The statistical significance of the difference in pressure anomalies in separate time periods was determined based on the use of the Student's $t$-test for two independent samples: $t=\left(x_{1}-x_{2}\right) / \sqrt{\left(s_{1}{ }^{2}+s_{2}{ }^{2}\right) / n}$, where $x_{1}, x_{2}$ are the mean values of the anomalies; $s_{1}{ }^{2}, s_{2}{ }^{2}$ are the variances; $n$ is the number of years in periods.

\section{Mean large-scale pressure fields corresponding to the winds of main directions}

Here we consider the relationship between the prevailing wind over the Black Sea and the large-scale distribution of the sea level pressure using the data with $6 \mathrm{~h}$ interval.

Mean pressure fields calculated for each wind direction are characterized by a certain position of large-scale anticyclones and cyclones (Fig. 2). Winds of the northern, northeastern and eastern directions are formed on the periphery of anticyclones located to the northwest, north and northeast of the Black Sea, respectively. At this time, a low pressure area is located to the south and southwest of the sea. Southeastern winds are formed when the anticyclone area is located eastwards of the Black Sea, and southerly winds - when the anticyclone area is located eastwards of the Caspian Sea. At this time, westwards of the Black Sea a low pressure area is located. The south-western and western wind flows above the sea are due to the location of extensive cyclones over the European territory, while high-pressure area to the south-eastwards and southwards of the sea are located. The location of anticyclones in European territory to the west of the Black Sea is accompanied by the northwestern winds above the sea. 

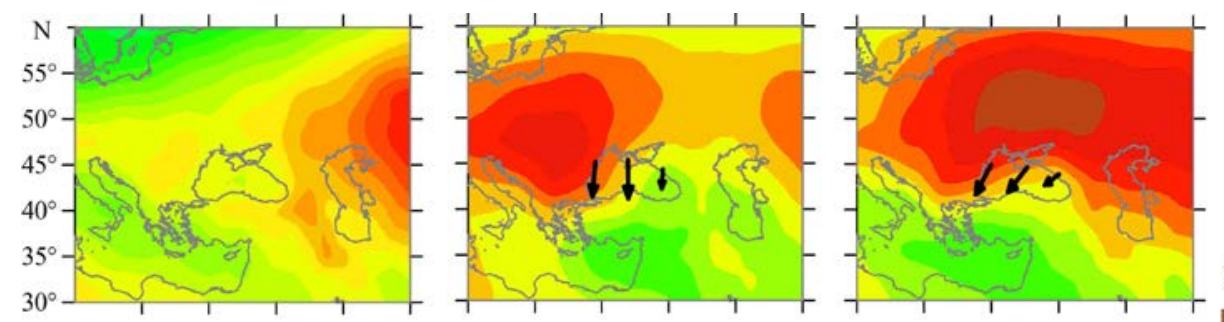

$\mathrm{hPa}$
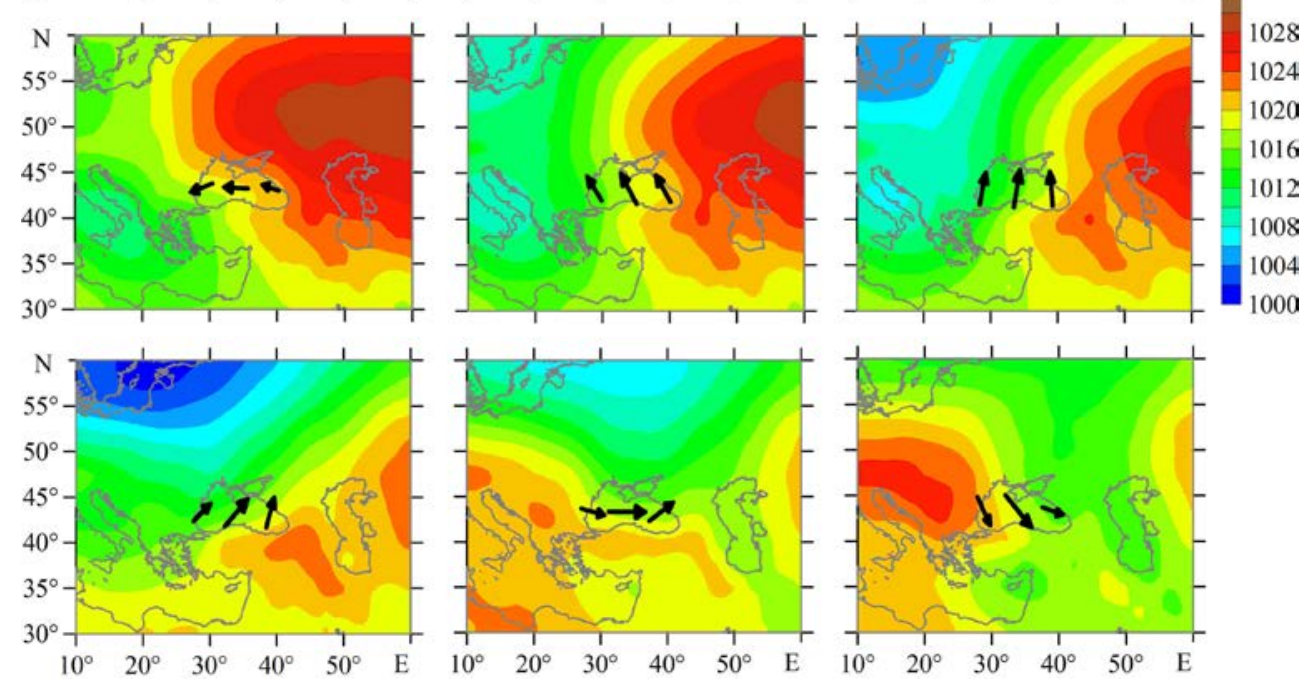

F i g. 2. Multiyear average sea level pressure field (top left figure) and average sea level pressure fields corresponding to the winds of the main geographic directions (indicated by the arrows) in January - February

In all these cases, the sea is located in the boundary zone between the areas with high and low sea level pressure (Fig. 2), and the wind velocity depends on the magnitude of the pressure gradient.

Despite the fact that the average sea level pressure fields were constructed from a long series of data for January - February 1948-2018, the obtained results are in good agreement with the types of synoptic processes identified in $[9,10]$ using synoptic maps for 10-year period 1946-1955 without division into seasons. Thus, the direction of the wind flow above the sea is determined by large-scale synoptic processes, and the resulting pressure fields are typical distributions corresponding to the winds of the main geographic directions.

\section{Relationship between the wind stress curl and wind regime}

Now we consider the relationship between the basin-averaged curl and the wind direction based on 6-hour wind velocity data.

On average, the largest positive curl values (cyclonic curl) are observed at the winds with an eastern component in the velocity vector (table). The maximum value is observed during the northeastern winds, mainly due to the occurrence of inhomogeneity in the wind field when flowing around the Caucasus and Pontic 
mountains $[8,17]$. The greatest anticyclonic (negative) curl takes place at the winds with a westerly component, with a maximum during western winds, which is also due to the orography of coastal regions. The curl, which is close to zero, is observed during southern winds.

Winter wind directions frequency, basin-average wind stress curl $\operatorname{rot}_{\mathrm{z}} \tau$ in January February, and correlation coefficients $R$ between their time series in 1948-2018

\begin{tabular}{ccccc}
\hline Wind direction & Wind directions frequency, $\%$ & $\operatorname{rot}_{\mathrm{z}} \tau \times 10^{-7} \mathrm{~N} / \mathrm{m}^{3}$ & $R$ \\
\hline $\mathrm{N}$ & 13.9 & 0.53 & 0.04 \\
$\mathrm{NE}$ & 18.2 & 1.81 & 0.77 \\
$\mathrm{E}$ & 9.1 & 1.72 & 0.75 \\
$\mathrm{SE}$ & 6.2 & 0.75 & 0.37 \\
$\mathrm{~S}$ & 10.2 & 0.18 & 0.01 \\
$\mathrm{SW}$ & 17.1 & -0.48 & -0.57 \\
$\mathrm{~W}$ & 13.5 & -0.87 & -0.70 \\
$\mathrm{NW}$ & 11.9 & -0.47 & -0.54 \\
$\mathrm{NE}+\mathrm{E}$ & 27.3 & 1.78 & 0.87 \\
$\mathrm{SW}+\mathrm{W}$ & 30.6 & -0.65 & -0.77 \\
\hline
\end{tabular}

Further we will consider the relationship of curl with the frequency of the winds of the main geographic directions based on the analysis of their time series.

Interannual variability of wind directions frequency. Time series of the average frequency of the winds of the main directions for January - February are given in Fig. 3. The occurrence frequency of winds with the easterly (Fig. 3, a) and westerly (Fig. 3, b) components in the velocity vector has opposite tendencies of variability, namely: the frequency of the northeastern, eastern and southeastern winds in the period under consideration was higher in the 1960s and early 1970s and less high - since the mid-1980s. The opposite tendency is observed for the winds with a westerly component in the velocity vector. The frequency of northerly and southerly winds varies little over long time scales.

Interannual variability of wind stress curl. Winter interannual fluctuations of the basin-averaged curl (Fig. 4, a) are in good agreement with the variability of total frequency of the northeastern and eastern winds and are in an antiphase with the total frequency of the south-western and western winds (Fig. 4, b). 

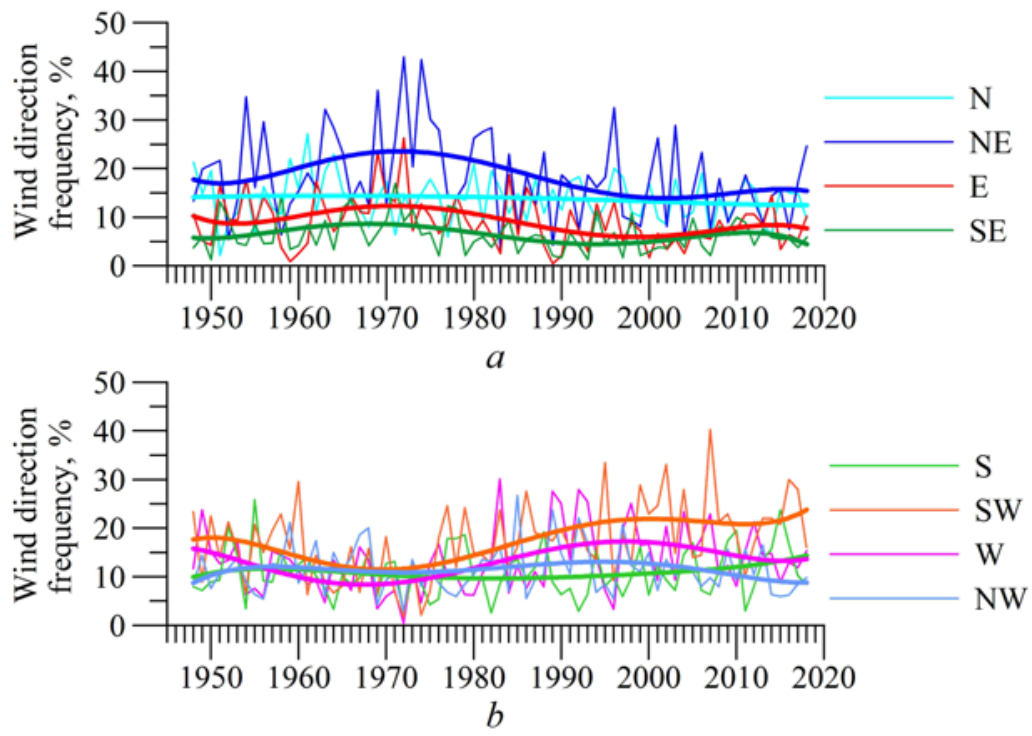

F i g. 3. Interannual variability of wind directions frequency (\%) in January - February (smoothing curves are the polynomials of the $5^{\text {th }}$ degree)

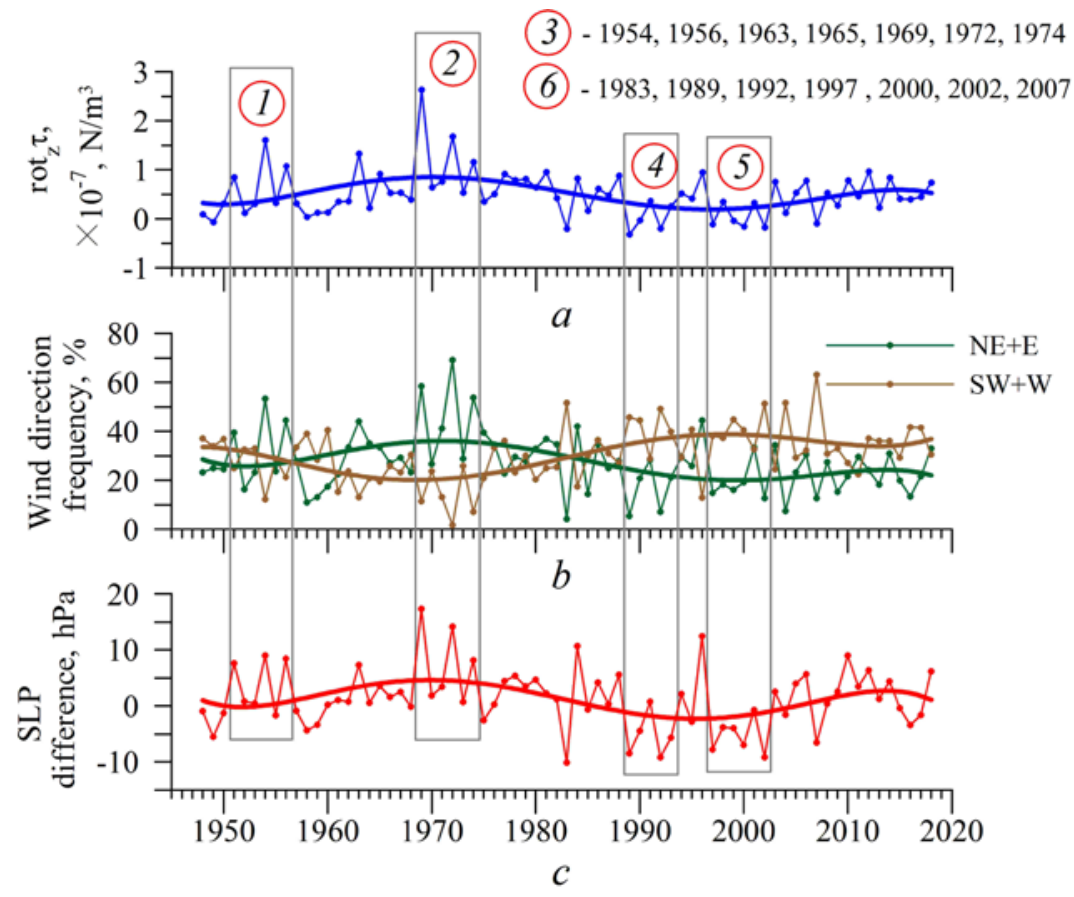

F i g. 4. Interannual changes of: the basin-average wind stress curl values $(a)$; total frequency of occurrence (\%) of the northeastern and eastern $(\mathrm{NE}+\mathrm{E})$, and southwestern and western $(\mathrm{SW}+\mathrm{W})$ winds (b); the difference in the surface sea level pressure values in regions $A$ and $B$ (see Fig. 5) (c) in January - February (smoothing curves are the polynomials of the $5^{\text {th }}$ degree). Time periods $1951-$ 1956, 1969-1974, 1989-1993 and 1997-2002 are indicated by numerals 1, 2, 4, 5, respectively; the sets of years on the top of the figure - by numerals 3 and 6 
In the mid-1950s and from the late 1960s to the mid-1970s the wind stress curl values were higher compared to the period from the late 1980s to the early 2000s, which indicates the presence of variability on climatic scales.

The correlation coefficients calculated between the time series of monthly average values of wind stress curl and wind frequency have high positive values for the northeastern (0.77) and eastern (0.75) winds and high negative values for the western $(-0.70)$ and southwestern $(-0.57)$ winds (table). The correlation coefficients with the northern and southern winds are close to zero. The calculation of the correlation with the total frequency of the eastern and north-eastern, as well as the western and south-western winds led to an increase in the correlation coefficients to 0.87 and -0.77 , respectively.

Thus, the northern, northeastern, western and southwestern winds make the greatest contribution to the variability of the wind stress curl in the Black Sea.

\section{Wind stress curl relationship with the large-scale pressure field}

In order to determine the types of synoptic processes in which an increase or decrease in cyclonic curl in the sea takes place, a map of the spatial distribution of the correlation coefficients between the monthly average series of the seaaverage wind stress curl and the pressure series at $2.5 \times 2.5^{\circ}$ grid nodes for January - February (Fig. 5) is created.

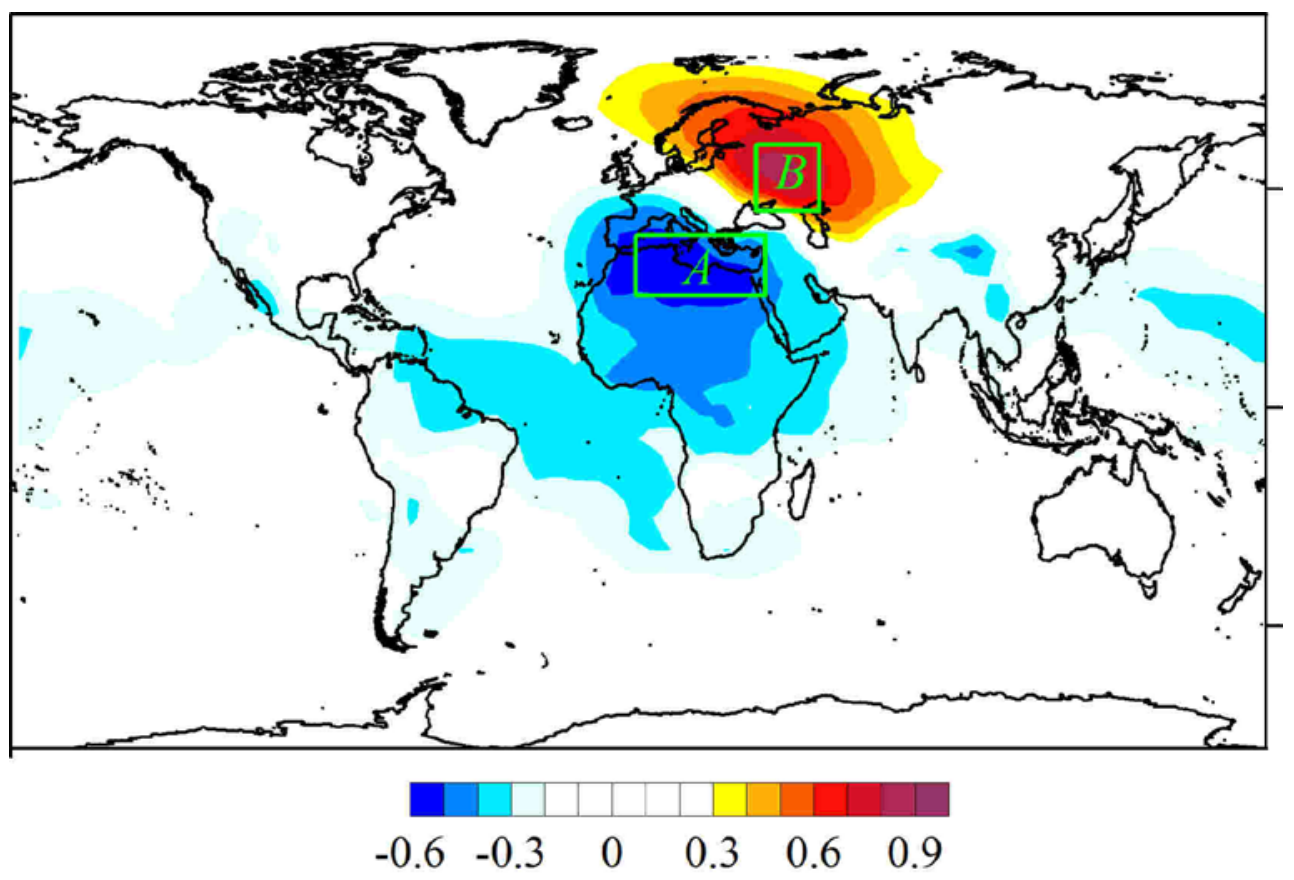

F i g. 5. Distribution of the correlation coefficients significant at the $99 \%$-confidence level between the time series of the wind stress curl in the Black Sea and the sea level pressure in January February for $1948-2018$. Region $45-60^{\circ} \mathrm{N}$ and $34-50^{\circ} \mathrm{E}$ is denoted by $A$, region $25-40^{\circ} \mathrm{N}$ and $10-35^{\circ}$ E - by $B$ 
The area with positive values of the correlation coefficient is located to the north, northeast of the sea with the center in the European part of Russia, with negative values - on the territory of the Mediterranean Sea and the northern part of the African continent. The maximum value of positive correlation is 0.84 , negative -0.57 . This result is in good agreement with a similar calculation performed according to the ERA Interim data in [13].

The obtained distribution corresponds to the type of synoptic processes accompanied by northeastern and eastern winds (Fig. 2), in which, on average, cyclonic wind stress curl prevails over the sea (Table). The distribution with the opposite sign of the correlation corresponds to situations with western and southwestern winds (Fig. 2), in which the anticyclonic curl prevails, on average, in the sea. Taking into account that high curl values are on average observed in alongshore areas when the wind flow around mountains (Fig. 1, $b-e$ ), it can be noted that the obtained relationship between the curl values with certain synoptic situations and a certain wind direction is mainly due to the orographic factor.

The time series of pressure gradient calculated as the difference between the average pressure values in the regions with the maximum correlation coefficients (denoted by letters $A$ and $B$ in Fig. 5) is shown in Fig. 4, c. Its correlation with the wind stress curl in the sea is 0.9 .

\section{Baric fields at high and low values of wind stress curl}

Further, the average large-scale pressure fields, which correspond to the extreme monthly average values of the wind stress curl, are analyzed. From the curl time series in Fig. 4, a, two periods, 1951-1956 and 1969-1974, containing high curl values and two periods, 1989-1993 and 1997-2002, containing low values were selected. We also selected two sets of years with extremely high $(1954,1956,1963,1965,1969,1972,1974)$ and extremely low (1983, 1989, 1992, 1997, 2000, 2002, 2007) wind stress curl values. For these periods and years, average pressure fields within the range $0-90^{\circ} \mathrm{N}, 100^{\circ} \mathrm{W}-$ $150^{\circ} \mathrm{E}$ with the center in the Black Sea region (Fig. 6) were plotted. Monthly average pressure data were used.

In the periods and years with wind stress curl high values (denoted by numbers 1, 2, and 3 in Figs. 4 and 6), the regional distribution of the mean sea level pressure corresponds to the types of synoptic processes with a predominance of northeastern and eastern winds above the sea (Fig. 2).

During these years, the size and depth of quasi-stationary baric centers above the North Atlantic (Azores High and Icelandic Low) decrease, and the area occupied by the seasonal Siberian High increases northward and expands to the east and west, covering the entire Asian and Eastern European part of Russia (Fig. 6). In such a baric environment, the Black Sea is located on the southwestern periphery of the Siberian High spur. Cold continental air from the center of Eurasia is brought here under effect of eastern winds. The Caucasus Mountains prevent their direct penetration to the Black Sea, which contributes to the formation of sharp temperature gradients between the sea and the land northwards of the eastern part of the sea and may be accompanied by an intensification of the monsoon effect, which makes an additional contribution to cyclonic curl. 

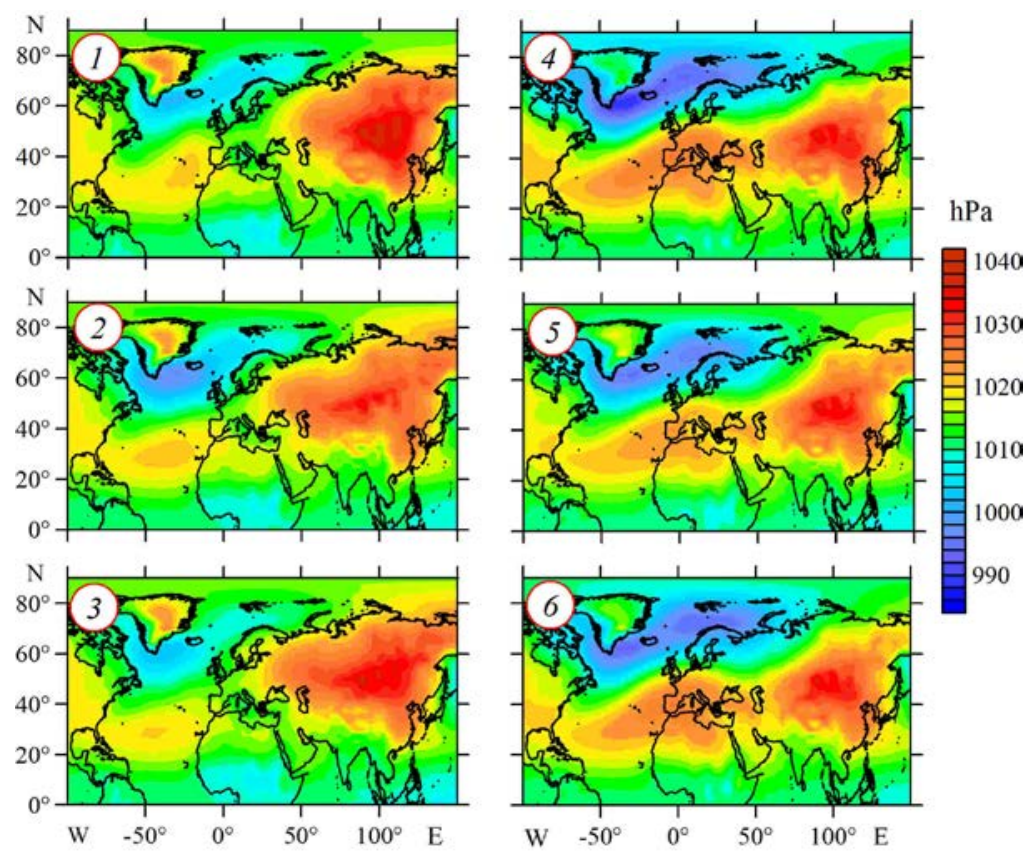

F i g. 6. Sea level pressure field in January - February averaged for the periods: 1 - 1951-1956; 2 1969-1974; 4 - 1989-1993; 5 - 1997-2002, and for the years: 3 - 1954, 1956, 1963, 1965, 1969, 1972, 1974; 6 - 1983, 1989, 1992, 1997, 2000, 2002, 2007

In periods and years with wind stress curl low values (indicated by numbers 4, 5, and 6 in Figs. 4 and 6), a decrease in the area occupied by the Siberian High is observed. Its northern boundary shifts to the south, and the pressure decreases at the European part of Russia (Fig. 6). The zone of the Icelandic Low effect is expanding to the northern part of Europe, the one of the Azores High - to the Mediterranean region. During such periods, the Black Sea is located on the eastern periphery of the Azores High spur. The high pressure strip connects the Azores High and Siberian High, located southwards of the sea. This pressure distribution provides the generation of winds with a western component in the velocity vector (Fig. 2). They bring warm air from the Atlantic into the region, softening winters, reducing sea-land temperature gradients, and thereby weakening the monsoon effect.

\section{Multi-decadal variability of large-scale fields of sea level pressure anomalies}

In order to analyze the causes of curl climatic variability, 30-year fields of sea level atmospheric pressure anomalies for 1951-1980 and 1981-2010 (Fig. 7, $a, b$ ) from the mean long-term field (Fig. 7, c) are considered. During the period under consideration, a change in the sign of the anomalies was observed in the northern and southern parts of both hemispheres. Further we will analyze the variability in the Northern Hemisphere. 


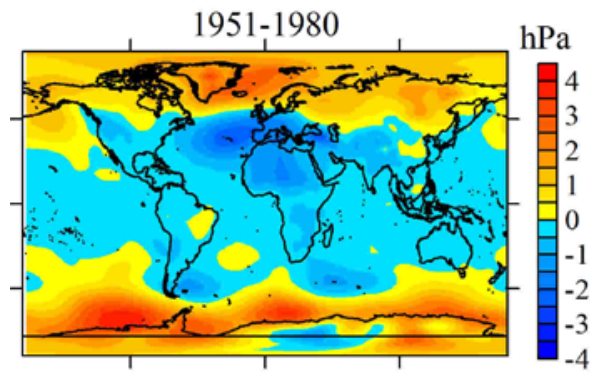

$a$

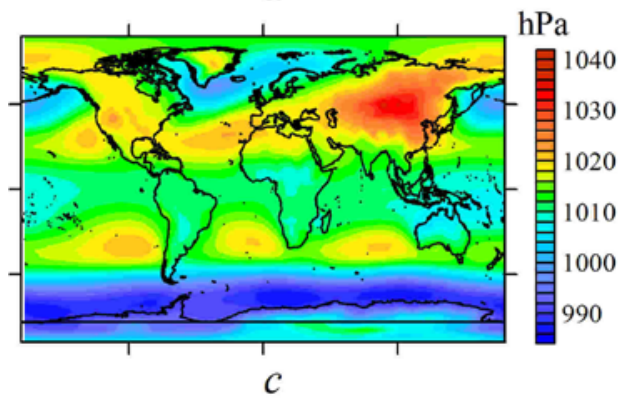

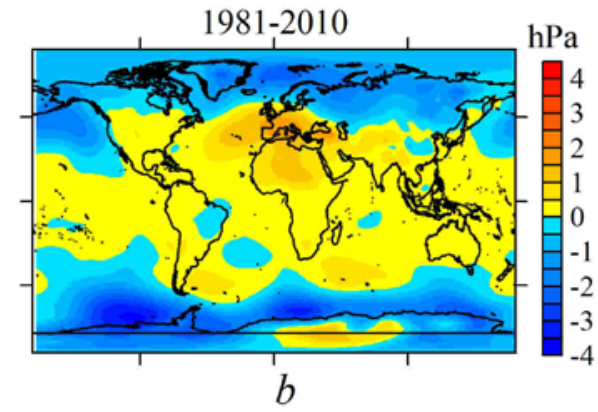

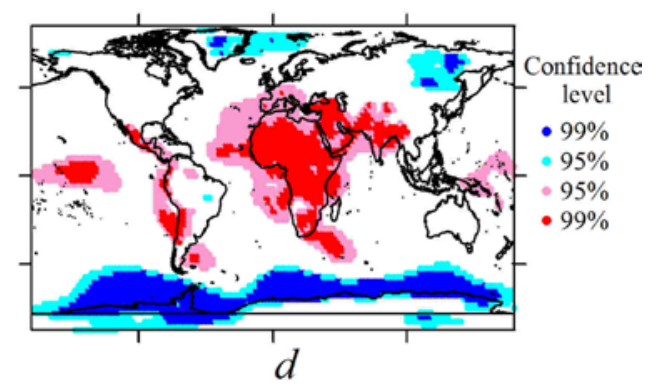

F i g. 7. Mean for 1951-1980 (a) and 1981-2010 (b) fields of the sea level pressure anomalies and mean for 1948-2018 sea level pressure $(c)$ in January - February; statistical significance of the differences in the pressure anomalies between $(b)$ and $(a)$ at the 99\%- and 95\%-confidence levels (pink and red show positive difference between the anomalies, blue and navy blue - negative one) (d)

In $1951-1980$ in a vast territory northwards of $40-50^{\circ} \mathrm{N}$ positive sea level pressure anomalies prevailed, and the area with negative anomalies occupied more southward territory, up to the equator (Fig. 7, a). This corresponds to a more frequent passage of anticyclones to the north of the sea, while the number of cyclones increased southwards of the sea (Fig. 2). This situation was accompanied by an increase in the frequency of winds with an eastern component in the velocity vector (Fig. 3; 4, b) and an increase in the positive wind stress curl (Fig. 4, $a$ ).

In 1981-2010 period in the northern part of the Northern Hemisphere, negative atmospheric pressure anomalies prevailed, in the southern - the positive ones (Fig. 7, b). This distribution corresponds to an increase in the number of cyclones in the northern part of the hemisphere and anticyclones in the southern one (Fig. 2). This was accompanied by an increase in the frequency of winds with a western component in the velocity vector (Fig. 3; $4, b$ ) and a weakening of the cyclonic wind stress curl (Fig. 4, $a$ ).

The areas with significant differences between the pressure anomalies in 1981-2010 and 1951-1980 are located mainly in low and high latitudes (Fig. 7, d). At middle latitudes, the differences in anomalies for the periods with 30-year averaging are insignificant. Taking into account this fact and the distribution of the correlation coefficients between curl and pressure (Fig. 5), it can be assumed that the pressure variability at middle latitudes mainly determines the synoptic variability and is reflected in the interannual fluctuations of the curl in the Black Sea. At the same time, pressure variability at lower latitudes - in the Mediterranean 
region and in northern Africa (Fig. $7, d$ ) - contributes not only to synoptic, but also to climatic multi-decadal curl variability.

The obtained inter-decadal variability of atmospheric pressure is in good agreement with the results of studies of pressure trends in the Northern Hemisphere. Negative trends in sea level pressure in the northern part of the Northern Hemisphere (northwards of the Black Sea) and positive trends in the southern part were obtained according to data from 1955-2004 [26] and 1951-2011 [27]. The Black Sea is located in mid-latitudes, and long-term opposite pressure changes to the north and the south of it are accompanied by a change in the wind regime in accordance with Fig. 2.

The analysis of storm tracks and the number of cyclones in the Northern Hemisphere for the winter months also confirms the results. Since the mid-1970s, an increase in the number of cyclones at high latitudes and a decrease in low latitudes of the Northern Hemisphere according to data from 1959-1997 [28] were observed. A decrease in cyclones over the territory of Turkey was noted in 1979-1995. [29]. All this indicates a decrease in the sea level pressure westwards of the Black Sea and an increase to the south in these years, which was accompanied by an increase in the frequency of winds with a western velocity component and a weakening of cyclonic curl.

\section{Conclusion}

The paper considers the relationship between long-term changes in the largescale pressure field, wind regime and wind stress curl in the Black Sea for the winter months.

The distribution of atmospheric pressure determines the direction of the wind above the sea, and the inhomogeneity of the wind velocity field is accompanied by the curl occurence. The sign and value of curl depend on the wind direction and, therefore, on the type of synoptic processes in the Black Sea region.

Interannual variability of wind stress curl in the sea has high positive correlation coefficients with the sea level pressure in the European territory of Russia and negative - with the pressure in the Mediterranean region. The curl correlation with the sea level pressure difference in these regions is 0.9. During the periods when positive pressure anomalies prevail northwards of the sea, and negative pressure anomalies to the south and southwest, the frequency of northeastern and eastern winds increases, which is accompanied by an increase in cyclonic curl. With the reverse pressure distribution, the frequency of the western and southwestern winds increases and the anticyclonic curl increases.

Inter-decadal curl variability demonstrates a relationship with the atmospheric pressure variability at low latitudes.

For a more complete study of the long-term variability of curl and wind regime in the sea and their relationship with the variability of baric fields, further studies with the use of the data for other seasons are required. 


\section{REFERENCES}

1. Stanev, E.V., 2015. Understanding Black Sea Dynamics: Overview of Recent Numerical Modeling. Oceanography, 18(2), pp. 56-75. https://doi.org/10.5670/oceanog.2005.42

2. Korotaev, G.K., 2001. On a Reason of Seasonal Variation of the Black Sea Circulation. Morskoy Gidrofizicheskiy Zhurnal, (6), pp. 14-20 (in Russian).

3. Efimov, V.V., Shokurov, M.V. and Barabanov, V.S., 2002. Physical Mechanisms of Wind Circulation Forcing over the Inland Seas. Izvestiya, Atmospheric and Oceanic Physics, 38(2). pp. 217-227.

4. Korotaev, G., Oguz, T., Nikiforov, A. and Koblinsky, C., 2003. Seasonal, Interannual, and Mesoscale Variability of the Black Sea Upper Layer Circulation Derived from Altimeter Data. Journal of Geophysical Research: Oceans, 108(C4), 3122. https://doi.org/10.1029/2002JC001508

5. Kubryakov, A.A. and Stanichny, S.V., 2015. Seasonal and Interannual Variability of the Black Sea Eddies and Its Dependence on Characteristics of the Large-Scale Circulation. Deep Sea Research Part I: Oceanographic Research Papers, 97, pp. 80-91. https://doi:10.1016/j.dsr.2014.12.002

6. Kubryakov, A.A., Stanichny, S.V., Zatsepin, A.G. and Kremenetskiy, V.V., 2016. Long-Term Variations of the Black Sea Dynamics and Their Impact on the Marine Ecosystem. Journal of Marine Systems, 163, pp. 80-94. https://doi.org/10.1016/j.jmarsys.2016.06.006

7. Efimov, V.V. and Anisimov, A.E., 2011. Climatic Parameters of Wind-Field Variability in the Black Sea Region: Numerical Reanalysis of Regional Atmospheric Circulation. Izvestiya. Atmospheric and Oceanic Physics, 47(3), pp. 350-361. doi:10.1134/S0001433811030030

8. Efimov, V.V. and Yurovsky, A.V., 2017. Formation of Vorticity of the Wind Speed Field in the Atmosphere over the Black Sea. Physical Oceanography, (6), pp. 3-11. doi:10.22449/1573-160X-2017-6-3-11

9. Chernyakova, A.P., 1965. Typical Wind Fields of the Black Sea. In: MGMO ChAM, 1965. [Collection of Works of the Basin Hydrometeorological Observatory of the Black and Azov Seas]. Leningrad: Gidrometeoizdat. Iss. 3, pp. 78-121 (in Russian).

10. Sorkina, A.I., Ed., 1974. [Climatic Handbook of the Black Sea]. Moscow: Gidrometeoizdat, 406 p. (in Russian).

11. Simonov, A.I. and Altman, E.N., Eds., 1991. [Hydrometeorology and Hydrochemistry of the USSR Seas. Vol. IV: Black Sea, issue 1: Hydrometeorological Conditions]. Leningrad: Gidrometeoizdat, 430 p. (in Russian).

12. Yarovaya, D.A. and Shokurov, M.V., 2012. Mesoscale Cyclonic Vortices Generated over the Black Sea near the Caucasian Coast. Morskoy Gidrofizicheskiy Zhurnal, (3), pp. 14-30 (in Russian).

13. Kubryakov, A., Stanichny, S., Shokurov, S. and Garmashov, A., 2019. Wind Velocity and Wind Curl Variability over the Black Sea from QuikScat and ASCAT Satellite Measurements. Remote Sensing of Environment, 224, pp. 236-258. https://doi.org/10.1016/j.rse.2019.01.034

14. Grigoriev, A.V. and Petrenko, L.A., 1999. [Black Sea as a Factor of Influence on Atmospheric Processes in the Region]. In: V.A. Ivanov, Ed., 1999. Ekologicheskaya Bezopasnost' Pribrezhnykh i Shel'fovykh Zon i Kompleksnoe Ispol'zovanie Resursov Shel'fa [Ecological Safety of Coastal and Shelf Zones and Comprehensive Use of Shelf Resources]. Sevastopol: ECOSI-Gidrofizika, pp. 17-26 (in Russian). 
15. Efimov, V.V. and Anisimov, A.E. 2011. Numerical Modeling of the Influence of Land-Sea Temperature Contrasts on the Atmospheric Circulation in the Black-Sea Region. Physical Oceanography, 21(4), pp. 221-229. doi:10.1007/s11110-011-9117-3

16. Capet, A., Barth, A., Beckers, J.-M. and Marilaure, G., 2012. Interannual Variability of Black Sea's Hydrodynamics and Connection to Atmospheric Patterns. Deep Sea Research Part II: Topical Studies in Oceanography, 77-80, pp. 128-142. https://doi:10.1016/j.dsr2.2012.04.010

17. Shokurov, M.V. and Shokurova, I.G., 2017. Wind Stress Curl over the Black Sea under Different Wind Regimes. Physical Oceanography, (6), pp. 12-23. https://doi.org/10.22449/1573-160X-2017-6-12-23

18. Shokurova, I.G., 2019. Interannual Variability of Wind Stress Curl in the Black Sea and Its Response to Changes in Prevailing Wind Frequency. IOP Conference Series: Earth and Environmental Science, 386, 012014. https://doi:10.1088/1755-1315/386/1/012014

19. Efimov, V.V. and Komarovskaya, O.I., 2018. Seasonal Variability and Hydrodynamic Regimes of the Novaya Zemlya Bora. Izvestiya, Atmospheric and Oceanic Physics, 54(6), pp. 581-593. https://doi.org/10.1134/S0001433818060051

20. Kalnay, E., Kanamitsu, M., Kistler, R., Collins, W., Deaven, D., Gandin, L., Iredell, M., Saha, S., White, G. [et al.], 1996. The NCEP/NCAR 40-Year Reanalysis Project. Bulletin of the American Meteorological Society, 77(3), pp. 437-472. https://doi.org/10.1175/15200477(1996)077<0437:TNYRP>2.0.CO;2

21. Dee, D.P., Uppala, S.M., Simmons, A.J., Berrisford, P., Poli, P., Kobayashi, S., Andrae, U., Balmaseda, M.A. and Balsamo, G., et al, 2011. The ERA-Interim Reanalysis: Configuration and Performance of the Data Assimilation System. Quarterly Journal of the Royal Meteorological Society, 137(656), pp. 553-597. doi:10.1002/qj.828

22. Fore, A.G., Stiles, B.W., Chau, A.H., Williams, B.A., Dunbar, R.S. and Rodríguez, E., 2014. Point-Wise Wind Retrieval and Ambiguity Removal Improvements for the QuikSCAT Climatological Data Set. IEEE Transactions on Geoscience and Remote Sensing, 52(1), pp. 51-59. doi:10.1109/TGRS.2012.2235843

23. Verhoef, A., Portabella, M. and Stoffelen, A., 2012. High-Resolution ASCAT Scatterometer Winds near the Coast. IEEE Transactions on Geoscience and Remote Sensing, 50(7), pp. 2481-2487. doi:10.1109/TGRS.2011.2175001

24. Polonskii, A.B. and Shokurova, I.G., 2009. Decadal Variability of Characteristics of the Black Sea Pycnocline and Geostrophic Circulation in the Wintertime. Russian Meteorology and Hydrology, 34(4), pp. 243-255. https://doi.org/10.3103/S1068373909040074

25. Large, W.G. and Pond, S., 1981. Open Ocean Momentum Flux Measurements in Moderate to Strong Winds. Journal of Physical Oceanography, 11(3), pp. 324-336. https://doi.org/10.1175/1520-0485(1981)011<0324:OOMFMI>2.0.CO;2

26. Bhend, J. and Whetton, P., 2013. Consistency of Simulated and Observed Regional Changes in Temperature, Sea Level Pressure and Precipitation. Climatic Change, 118(3), pp. 799-810. https://doi.org/10.1007/s10584-012-0691-2

27. Gillett, N.P., Fyfe, J.C. and Parker, D.E., 2013. Attribution of Observed Sea Level Pressure Trends to Greenhouse Gas, Aerosol, and Ozone Changes. Geophysical Research Letters, 40(10), pp. 2302-2306. https://doi.org/10.1002/grl.50500

28. McCabe, G.J., Clark, M.P. and Serreze, M.C., 2001. Trends in Northern Hemisphere Surface Cyclone Frequency and Intensity. Journal of Climate, 14(12), pp. 2763-2768. https://doi.org/10.1175/1520-0442(2001)014<2763:TINHSC>2.0.CO;2

29. Karaca, M., Deniz, A. and Tayanç, M., 2000. Cyclone Track Variability over Turkey in Association with Regional Climate. International Journal of Climatology, 20(10), pp. 12251236. https://doi.org/10.1002/1097-0088(200008)20:10<1225::AID-JOC535>3.0.CO;2-1 
About the authors:

Irina G. Shokurova, Research Associate, Marine Hydrophysical Institute of RAS (2 Kapitanskaya str., Sevastopol, 299011, Russian Federation), Ph. D. (Geogr.), Scopus Author ID: 25822860800, ORCID ID: 0000-0002-3150-8603, ResearcherID: C-8223-2016, igshokurova@mail.ru

Arseniy A. Kubryakov, Leading Research Associate, Marine Hydrophysical Institute of RAS (2 Kapitanskaya str., Sevastopol, 299011, Russian Federation), Ph. D. (Phys.-Math.), ORCID ID: 0000-0003-3561-5913, ResearcherID: F-8921-2014, arskubr@mhiras.ru

Mikhail V. Shokurov, Leading Research Associate, Marine Hydrophysical Institute of RAS (2 Kapitanskaya str., Sevastopol, 299011, Russian Federation), Dr. Sci.(Phys.-Math.), Scopus Author ID: 6602394600, ORCID ID: 0000-0003-1595-8281, ResearcherID: V-7160-2017, shokurov.m@gmail.com

Contribution of the co-authors:

Irina G. Shokurova - research problem statement, carrying out the calculations, analysis of the climatic variability of the sea level pressure and wind stress curl

Arseniy A. Kubryakov - research problem statement, analysis of the relationship between the wind stress curl and the centers of high atmospheric pressure - the Siberian High and Azores High

Mikhail V. Shokurov - general scientific guidance of the research

All the authors have read and approved the final manuscript.

The authors declare that they have no conflict of interest. 